\title{
Article \\ Anti-Apoptotic Effect of Flavokawain A on Ochratoxin-A-Induced Endothelial Cell Injury by Attenuation of Oxidative Stress via PI3K/AKT-Mediated Nrf2 Signaling Cascade
}

\author{
Peramaiyan Rajendran ${ }^{1, * \mathbb{D}}$, Abdullah M. Alzahrani ${ }^{1}$, Vishnu Priya Veeraraghavan ${ }^{2}$ and Emad A. Ahmed ${ }^{1,3}$ \\ 1 Department of Biological Sciences, College of Science, King Faisal University, Al Ahsa 31982, Saudi Arabia; \\ aalzahra@kfu.edu.sa (A.M.A.); eaahmed@kfu.edu.sa (E.A.A.) \\ 2 Department of Biochemistry, Saveetha Institute of Medical and Technical Sciences, Saveetha Dental College, \\ Saveetha University, Chennai 600077, India; vishnupriya@saveetha.com \\ 3 Laboratory of Molecular Physiology, Zoology Department, Faculty of Science, Assiut University, \\ Assiut 71515, Egypt \\ * Correspondence: prajendran@kfu.edu.sa; Tel.: +97-135-899-543
}

check for updates

Citation: Rajendran, P.; Alzahrani, A.M.; Priya Veeraraghavan, V.;

Ahmed, E.A. Anti-Apoptotic Effect of Flavokawain A on

Ochratoxin-A-Induced Endothelial Cell Injury by Attenuation of Oxidative Stress via PI3K/AKT-Mediated Nrf2 Signaling Cascade. Toxins 2021, 13, 745. https://doi.org/10.3390/toxins13110745

Received: 2 September 2021

Accepted: 13 October 2021

Published: 21 October 2021

Publisher's Note: MDPI stays neutral with regard to jurisdictional claims in published maps and institutional affiliations.

Copyright: (c) 2021 by the authors. Licensee MDPI, Basel, Switzerland. This article is an open access article distributed under the terms and conditions of the Creative Commons Attribution (CC BY) license (https:/ / creativecommons.org/licenses/by/ $4.0 /)$.

\begin{abstract}
This study investigates the endothelial protective activity of flavokawain A (FKA) against oxidative stress induced by ochratoxin A (OTA), which acts as a mycotoxin, and its primary mechanisms in in vitro models. Reactive oxygen species, in general, regulate oxidative stress that significantly contributes to the pathophysiology of endothelial dysfunctions. OTA exerts toxicity through inflammation and the accumulation of ROS. This research is aimed at exploring the defensive function of FKA against the endothelial injury triggered by OTA through the Nrf2 pathway regulated by PI3K/AKT. OTA exposure significantly increased the nuclear translocation of NFKB, whereas we found a reduction in inflammation via NFKB inhibition with FKA treatment. FKA increased the PI3K and AKT phosphorylation, which may lead to the stimulation of antioxidative and antiapoptotic signaling in HUVECs. It also upregulated the phosphorylation of Nrf2 and a concomitant expression of antioxidant genes, such as HO-1, NQO-1, and $\gamma$ GCLC, depending on the dose under the oxidative stress triggered by OTA. Knockdown of Nrf2 through small interfering RNA (siRNA) impedes the protective role of FKA against the endothelial toxicity induced by OTA. In addition, FKA enhanced $\mathrm{Bcl} 2$ activation while suppressing apoptosis marker proteins. Therefore, FKA is regarded as a potential agent against endothelial oxidative stress caused by the deterioration of the endothelium. The research findings showed that FKA plays a key role in activating the p-PI3K/p-AKT and Nrf2 signaling pathways, while suppressing caspase-dependent apoptosis.
\end{abstract}

Keywords: flavokawain A; ochratoxin A; oxidative stress; apoptosis; Nrf2

Key Contribution: FKA a potential inhibitory effect of apoptosis against mycotoxin induced toxicity.

\section{Introduction}

The endothelium helps provide appropriate hemostatic balance. Vascular endothelial cells constitute the inner cellular lining of the circulatory system. The unique functions of these cells are important to the vascular biology that deals with hemostasis, regulation of blood vessel tone, kidney glomeruli functions such as fluid filtration, trafficking of hormone and neutrophil. According to researchers in this field, the endothelium represents various homeostatic functions [1-4]. The main pathophysiological mechanisms of a number of diseases are endothelial dysfunction and oxidative stress, including hypertension, atherosclerosis, dyslipidemia, diabetes, cardiovascular disease, renal failure, and ischemiareperfusion injury [5-8]. When present in excess, reactive oxygen species (ROS) modulate cellular function, receptor signals, and immune responses, causing progressive endothelial damage through growth and migration of vascular smooth muscle and inflammation 
cells. The extracellular matrix is then altered, endothelial cells are apoptosed, transcription factors (NFkB, AP-1) are activated, and inflammatory cytokines are overexpressed [9]. Increased oxidative stress in vascular tissues is caused by ROS-producing enzymes, such as NADPH oxidase (Nox), xanthine oxidase, and the mitochondrial respiratory chain. Several superoxide anions are known to react directly with NO by producing peroxynitrite $\left(\mathrm{ONOO}^{*}\right)$, which is believed to uncouple endothelial nitric oxide synthase (eNOS) and cause an NO-producing enzyme to become an ROS-producing enzyme, thus accelerating the atherosclerotic process [10].

Ochratoxin A (OTA) is a powerful mycotoxin found in many foods and feed. It is responsible for both chronic and sub-chronic toxicity, including nephrotoxicity, hepatotoxicity, teratogenicity, and immunotoxicity to both humans and various animals [11]. Chronic toxicity is one of the main causes of OTA, resulting from its prolonged intake in minimum amounts. OTA associates itself with hepatotoxic, genotoxic, carcinogenic, nephrotoxic, teratogenic, and immunosuppressive effects, affecting humans as well as various animals [12,13]. The effects of OTA are widely known in the research community; however, researchers have not completely clarified the molecular mechanisms underlying the damage. However, there is currently no definitive line of evidence for endothelial dysfunction caused by OTA exposure. In the present study, we evaluate endothelial dysfunction caused by OTA through oxidative stress and the protection against oxidative stress induced by OTA in endothelial cells by using natural compounds. OTA exposure (in vitro or in vivo) has generally been linked to oxidative damage (lipids, proteins, and DNA) and the overproduction of ROS [14]. This particular mycotoxin may also decrease the antioxidant defense in cells by reducing GSH and cytoprotective enzymes [11]. Furthermore, it significantly reduces the expression of genes that consist of antioxidant regulatory elements (AREs) and causes oxidative stress in the kidney tissues. Transcription factors, such as NFE2-related factor 2 (NRF2), identify specific elements, including AREs, and contribute to the regulation of antioxidant enzymes, cell protection, and genes encoding detoxification [15]. The PI3K/AKT pathway also provides cellular defense against oxidative stress and inflammatory stimuli. According to many studies, various signal transduction mechanisms, including PI3K/AKT, influence Nrf2 to detach from Keap1 and provide successive signals to trigger activation of antioxidant enzymes [15]. These studies have also proved that oxidative stress results in the decreased regulation of PI3K/Akt signaling for cell survival. Therefore, regulating the routes of signaling pathways, such as PI3K/Ak,t is a potential way to prevent hepatic apoptosis induced by ROS [16]. Subsequently, the inhibition of oxidative stress mediated by OTA can emerge as a potential therapeutic strategy for vascular dysfunction treatment. Numerous studies have investigated the endothelial protective effects of natural compounds against liver injury induced by toxic chemicals, which have been attributed to the intrinsic antioxidant properties [8,11,15,17]. Recently, Zhai et al. demonstrated that a dietary supplementation of curcuminoid composition (CURC) not only reversed the biochemical changes in serum but also ameliorated liver oxidative injury in OTA-treated white Pekin ducklings (for 3 weeks) [17].

Flavokawain A (FKA), also called kava-kava, is a natural chalcone derived from Piper methysticum Forst [18]. Age-standardized cancer cases in three kava-consuming Pacific countries (Fiji, Samoa, and Vanuatu) were reported to be significantly lower when compared to those of their neighboring countries (Australia and New Zealand). Multiple secondary metabolites, such as chalcones (flavokawains), lactones (kavalactones), and alkaloids in kava extracts, contribute to their therapeutic actions. Until now, researchers have identified only three kinds of flavokawains (FKA, FKB, and FKC). Among these types, FKA is considered the predominant chalcone, accounting for about $0.46 \%$ of kava extracts [19]. According to earlier studies, FKA selectively inhibits cancer cell growth with a zero or low effect on the progression of various tumor cells [20,21]. Dietary feeding of mice with FKA had no negative effects on the key functions of the organs; instead, it generated phase II antioxidant enzymes in the lung, liver, bladder, and prostate tissues [22]. However, researchers have not yet investigated FKA effects on damages to the vascular 
system and apoptosis-related signaling molecules. In the current study, we propose the hypothesis that FKA can mitigate oxidative stress triggered by OTA and Nrf2 signaling mediated by PI3K/AKT, which, in turn, will prevent endothelial dysfunction in HUVECs. We also found the important molecular proteins that demonstrate the anti-apoptotic role of FKA and activate Nrf2 signaling on OTA induced endothelial damage.

\section{Results}

\subsection{Effects of FKA on the Viability of HUVECs with or without OTA Stimulation}

Before exploring the structure of FKA (Figure 1A), we fixed the effective concentration of OTA at $10 \mu \mathrm{mol}$ based on the dose-response (Figure 1B). HUVECs were treated with rising FKA concentrations (0-50 $\mu \mathrm{mol}$ ) for $24 \mathrm{~h}$ to determine the cytotoxic effect on these cells. Based on the results of the MTT assay, the viability of HUVECs was the same (100\%) following the treatment with FKA, indicating that, up to $50 \mu \mathrm{mol}$, FKA did not generate any cytotoxic effects (Figure 1C). This was followed by a further evaluation of the impact of FKA $(0-25 \mu \mathrm{mol})$ on the cell viability and morphology of HUVECs with or without OTA $(10 \mu \mathrm{mol})$ induction. Cell pre-treatment with FKA $(0-25 \mu \mathrm{mol})$ strongly suppressed the OTA-induced $(10 \mu \mathrm{mol})$ viability of HUVECs (Figure 1D). Images obtained from optical microscope did not reveal any morphological changes after FKA treatment (Figure 1E). These findings indicated that FKA had no cytotoxic effects on HUVECs.

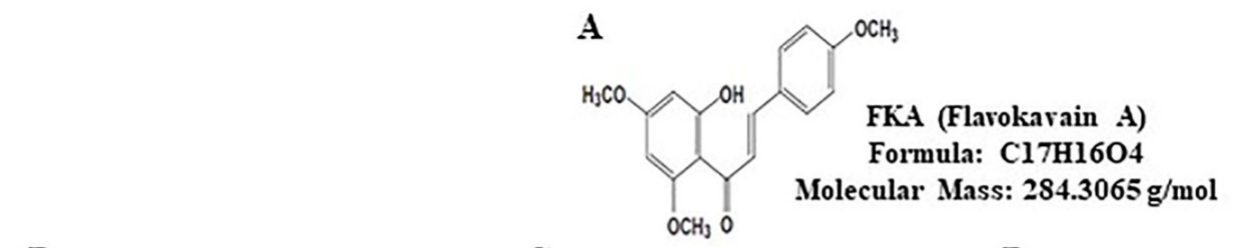

B

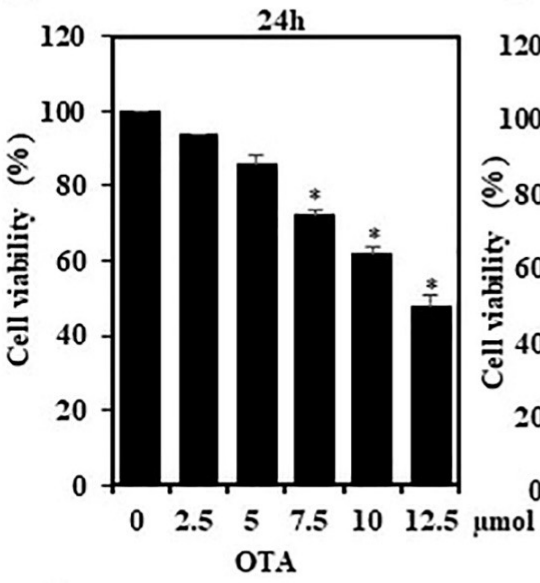

$\mathbf{E}$

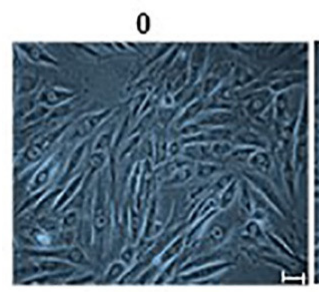

C

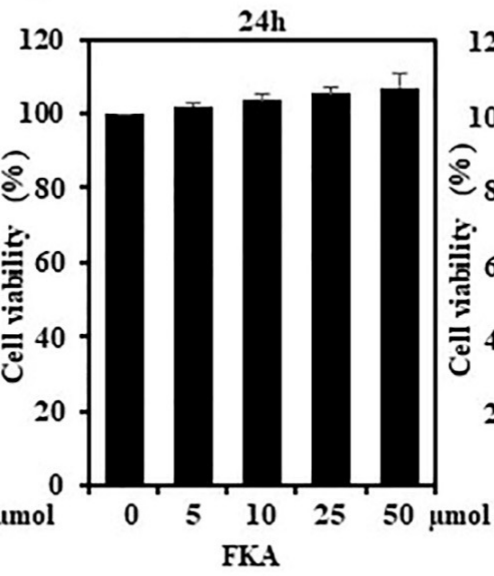

D

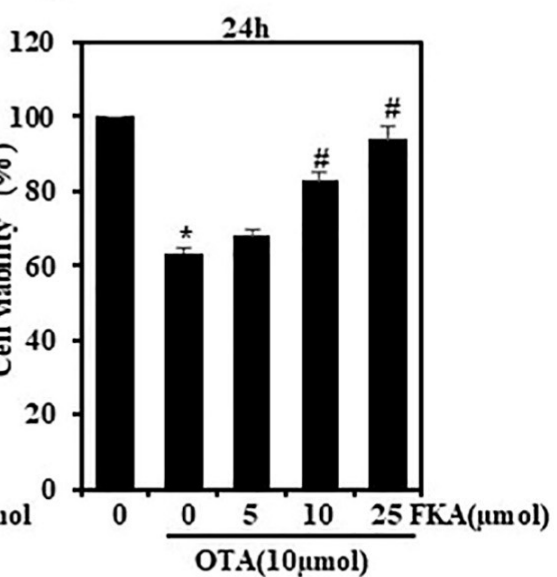

OTA $(10 \mu \mathrm{mol})$

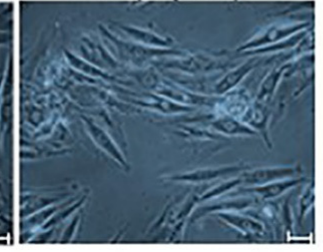

OTA (12.5umol)

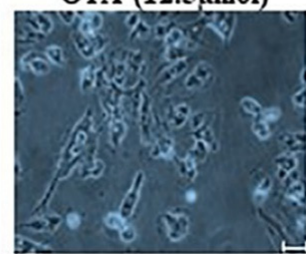

FKA $(25 \mu \mathrm{mol})$ OTA (10umol)

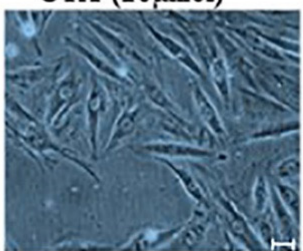

Figure 1. Effect of OTA and FKA on cell viability as calculated by MTT assay. (A) Chemical structure of FKA. (B) Cell viability was treated with different OTA concentrations $(2.5-12.5 \mu \mathrm{mol})$ for $24 \mathrm{~h}$. (C) Cell viability was determined with different FKA concentrations (5-50 $\mu \mathrm{mol})$ for $24 \mathrm{~h}$. Cells were pre-treated with FKA $(5,10$, and $25 \mu \mathrm{mol}$ for $2 \mathrm{~h})$ and then stimulated with or without OTA $(10 \mu \mathrm{mol})$ for $24 \mathrm{~h}$. (D) Morphological changes in HUVECs. (E) Effect of FKA on OTA induced cells morphology for $24 \mathrm{~h}$. ${ }^{*} p<0.05$ denotes significant variations in comparison to control. \# $p<0.05$ denotes significant variations as compared to OTA alone and FKA with OTA treatment groups. 


\subsection{Effect of FKA on the Activation of ROS-Mediated NFKB and Pro-Inflammatory Cytokines against OTA-Induced HUVECs}

The transcription factor NFKB regulates various factors of innate and adaptive immune functions. It also acts as a key mediator of the response to inflammation [23]. In this experiment, we examined NFKB function in suppressing inflammation in the endothelium, which was pretreated with FKA and stimulated by OTA. Data from Western blot collected from the extracts of the nuclear protein of HUVECs illustrated that OTA $(10 \mu \mathrm{mol})$ stimulation triggered a significant rise in the levels of p65 (Figure 2A). Further, we examined the effects of FKA on pro-inflammatory cytokine such as Cox-2 and TNF- $\alpha$ expression. Data generated from Western blot also demonstrated that OTA $(10 \mu \mathrm{mol})$ stimulation overexpressed the COX-2 and TNF- $\alpha$ expressions (Figure 2B). However, the presence of FKA in higher concentrations $(25 \mu \mathrm{mol})$ significantly suppressed this effect. It consequently suggested that the transcriptional activation of $\mathrm{p} 65$ was suppressed by FKA, which further suppressed the expressions of inflammatory enzymes and cytokines. To reconfirm our findings, we tested secretion pro-inflammatory cytokines using ELISA. It was observed that OTA stimulation only enhanced the production of TNF- $\alpha$, IL- 6 , and IL-1 $\beta$ cytokines (Figure 2C-E). However, the pretreatment with FKA remarkably suppressed the production of pro-inflammatory cytokines in a dose-dependent manner, thereby indicating the defensive action of FKA against the inflammation in HUVECs triggered by OTA.

A

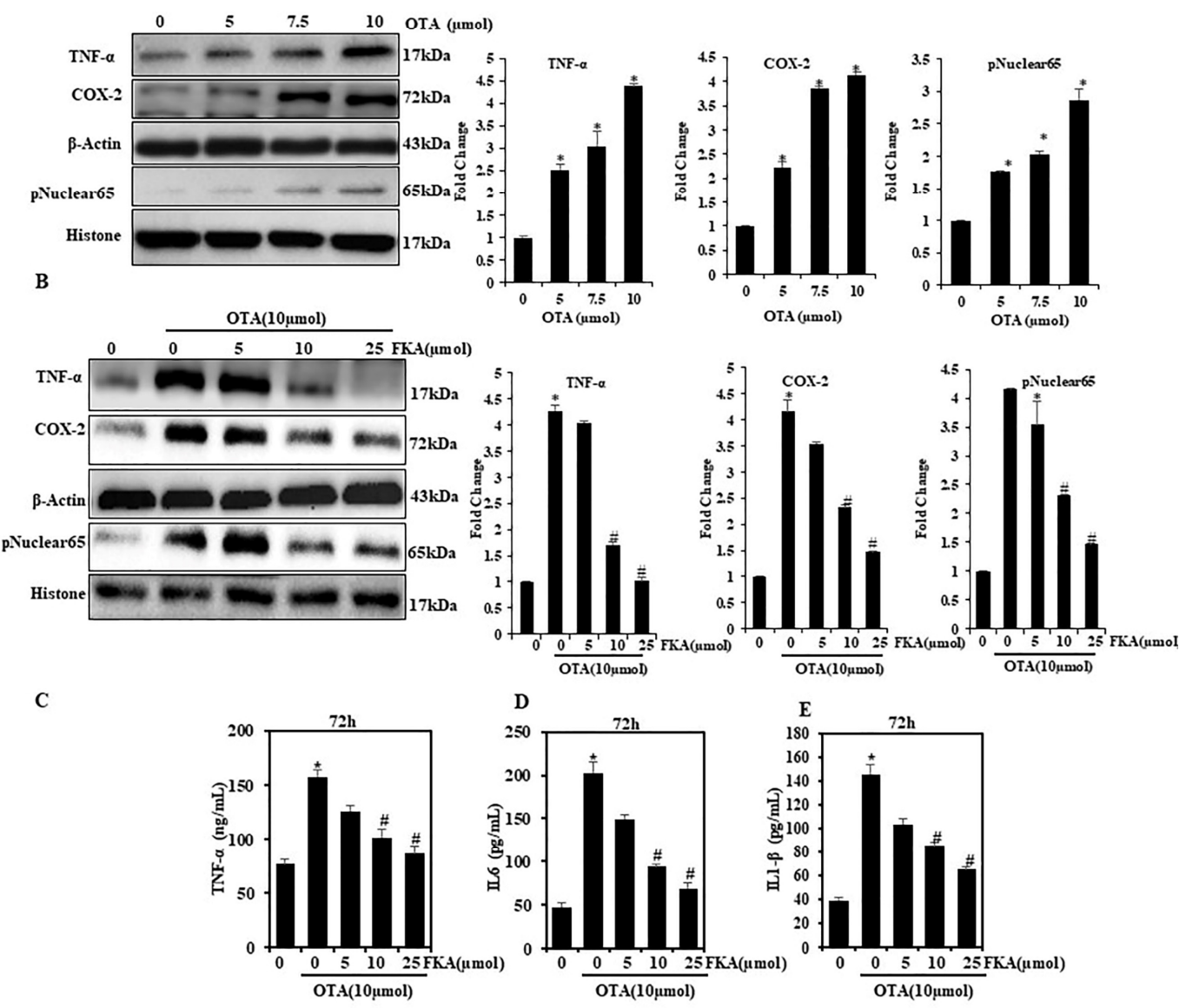

Figure 2. OTA-stimulated NFKB activation and pro-inflammatory cytokine expressions were suppressed in FKA-pretreated HUVECs. (A) HUVECs were treated with OTA (0, 5-10 $\mu \mathrm{mol})$ for $24 \mathrm{~h}$ for the Western blot analysis of pNFkB (p65), COX-2, and TNF- $\alpha$ expression. (B) Pretreatment occurred with FKA (5-25 $\mu \mathrm{mol})$ for $2 \mathrm{~h}$ and stimulated with OTA (10 $\mu \mathrm{mol})$ for $24 \mathrm{~h}$ for the Western blot analysis of pNFKB (p65), COX-2, and TNF- $\alpha$ level. (C-E) The secretions of TNF- $\alpha$, IL-6, and IL-1 $\beta$ were assayed with commercial ELISA kits. ${ }^{*} p<0.05$ denotes significant variations compared with the control. \# $p<0.05$ denotes significant variations as compared to OTA alone and FKA with OTA treatment groups. 


\subsection{FKA Protects the Endothelium against OTA-Induced Apoptosis}

Apoptosis remains a crucial indicator of OTA-induced vascular toxicity, which can also be worsened by uncontrolled oxidative stress and inflammation. We directly analyzed the anti-apoptotic capacity of FKA through terminal deoxynucleotidyl transferase dUTP nickend labeling (TUNEL) staining, showing reduced TUNEL-positive nuclei in OTA-treated cells (Figure 3A,B). These results showed that FKA inhibited OTA-induced apoptosis. The expression of apoptosis-related proteins, such as Bcl-2, demonstrated OTA-induced apoptosis in HUVECs via potential downregulation of protein expression levels (Figure 3C). FKA treatment, on the other hand, upregulated the proteins for cell survival, thereby preventing apoptosis. Our data from Western blot analysis also demonstrated changes in the expression of cleaved caspase- 3 and cleaved PARP - the two proteins associated with apoptosis. Although OTA upregulated the expression of these proteins, different concentrations of FKA downregulated the expression levels (Figure 3C).

A
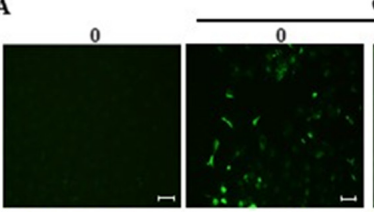

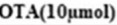
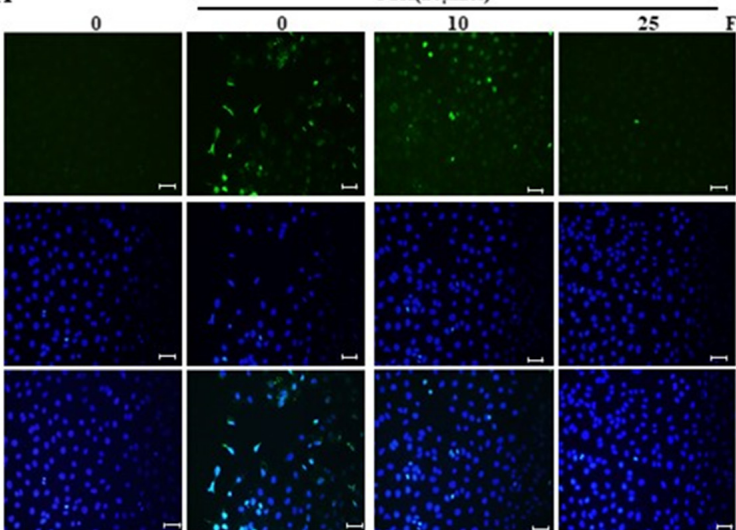

$A(\mu \mathrm{mol})$

B

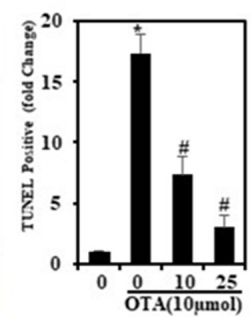

C

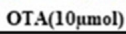
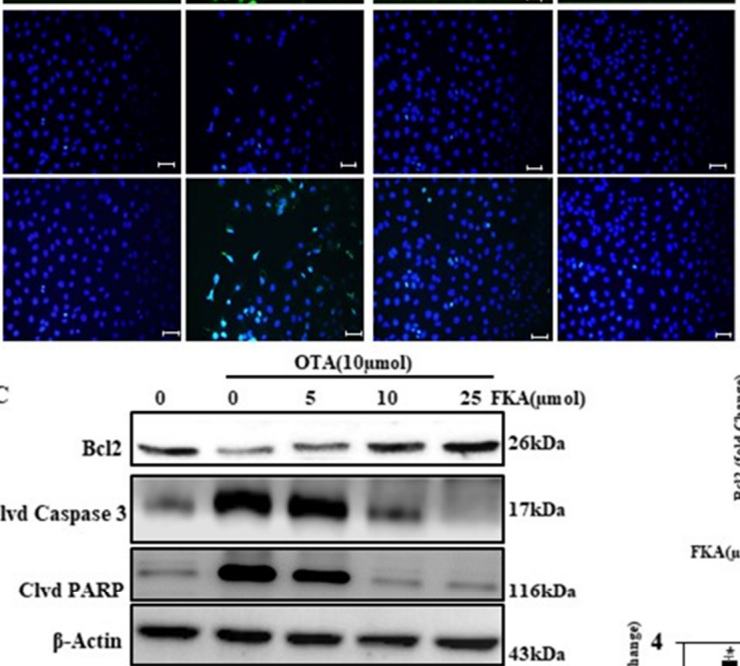

D
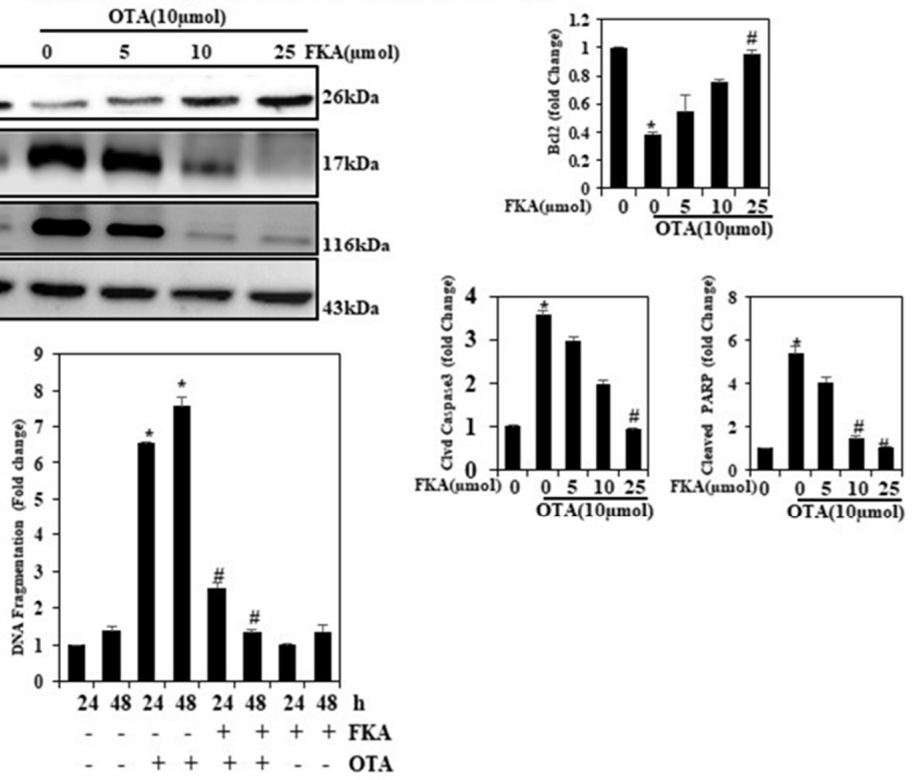

Figure 3. FKA inhibits apoptosis in endothelial cells. Cells were pretreated with FKA $(0,10$ and $25 \mu \mathrm{mol}$ for $2 \mathrm{~h})$ followed by induction with OTA $(10 \mu \mathrm{mol})$ for $24 \mathrm{~h}$. (A) TUNEL assay. In the microscope fields $(\times 400$ magnification $)$ the green fluorescence indicates the number of TUNEL-positive cells from three separate samples. (B) The fold change of apoptotic cells. (C) Bc-2, cleaved caspase-3, and PARP were monitored using Western blot analyses. Relative changes in Bcl-2, cleaved caspase-3, and PARP protein bands were measured by commercially available quantitative software (AlphaEase), with controls representing 1-fold. (C) Cells were pretreated with FKA $(0,10$, and $25 \mu \mathrm{mol}$ for $2 \mathrm{~h}$ ) followed by induction with OTA $(10 \mu \mathrm{mol})$ for the indicated times. (D) Apoptosis was measured by the degree of DNA fragmentation in the cytoplasm of cells treated with FKA. ${ }^{*} p<0.05$ represents significant variations compared with the control. \# $p<0.05$ denotes significant variations as compared to OTA alone and FKA with OTA treatment groups. 


\subsection{FKA Inhibits Apoptosis in HUVEC Line}

DNA fragmentation is one of the characteristic hallmarks of apoptosis. As mentioned above, we examined DNA fragmentation using a cell death detection ELISA kit [8]. OTAtreated cells saw a significantly increased DNA fragmentation, whereas FKA generated significant 5- and 7-fold decreases in DNA fragmentation in HUVECs (Figure 3D), following treatment for 24 and $48 \mathrm{~h}$, respectively, in comparison to the cells treated with the combination of FKA and OTA. This indicated that FKA was a potent inhibitor of apoptosis in OTA-induced oxidative stress in vascular endothelial cells.

\subsection{Effect of FKA on ROS Generation against OTA-Induced Endothelial Cells}

The activation of Nrf2 regulates various signaling cascades, such as ROS. These are considered as natural oxygen metabolism by-products and play a key role in homeostasis and cell signaling. Low concentrations of ROS play an indispensable role in intracellular signaling and defense against pathogens, while higher amounts of ROS play a role in a number of human diseases [24]. Like other chalcones, FKA demonstrated effective antioxidant and chemo-protective properties in various experiments, in vitro as well as in vivo $[25,26]$. In an earlier study, we showed the protective role of FKA in vascular HUVECs in a case of oxidative stress induced by TGF- $\beta 1(10 \mathrm{ng} / \mathrm{mL})$ [18]. In this study, we investigated the effect of ROS generation induced by OTA on HUVECs. We used the method of DCFH2-DA fluorescence to measure the intracellular generation of ROS. Endothelial cells were subjected to FKA pretreatment in varying concentrations $(0,10$, and $25 \mu \mathrm{mol}$ for $2 \mathrm{~h}$ ) followed by OTA induction $(10 \mu \mathrm{mol})$ for $24 \mathrm{~h}$ (Figure $4 \mathrm{~A})$. We then used these cells to calculate the levels of intracellular ROS accumulation. Data signified that dose-dependent FKA pretreatment remarkably suppressed ROS generation triggered by OTA, thereby confirming its role in blocking ROS generation in HUVECs.

\subsection{FKA Upregulates Nrf2, HO-1, and $\gamma$-GCLC in HUVECs}

According to earlier studies, Nrf2 is involved in the anti-inflammatory process, as it improves inflammatory cell recruitment and enables gene expression regulation AREs. Keap-1/Nrf2/ARE is primarily an antioxidant pathway and regulates anti-inflammatory gene expression, which further suppresses inflammation progression [27]. Endothelial cells were pretreated with different FKA concentrations $(0,5,10$, and $25 \mu \mathrm{mol}$ for $2 \mathrm{~h}$ ) and inducted with OTA $(10 \mu \mathrm{mol})$ for $24 \mathrm{~h}$. We also measured several antioxidant protein expressions. Western blot data obtained from this study demonstrated that dose-dependent FKA treatment upregulated the nuclear Nrf2, HO-1, NQO-1, and $\gamma$-GCLC expressions, and we observed the maximum expressions observed at $25 \mu \mathrm{mol}$ (Figure 4B). We measured the data as the fold over basal levels of the expression of antioxidant proteins at varying dose points. This was followed by the normalization of these points using the histone and $\beta$-actin internal controls, which are expressed as the ratio value. Data revealed a differential yet substantial FKA effect on the nuclear Nrf2, HO-1, $\gamma$-GCLC, and NQO-1 expression patterns.

\subsection{Effect of FKA on OTA-Induced GSH Levels in Endothelial Cells}

FKA is considered to play a remarkable role in triggering antioxidant proteins. Consequently, we measured the GSH levels of endothelial cells pretreated with different FKA concentrations $(0,5,10$, and $25 \mu \mathrm{mol}$ for $2 \mathrm{~h})$ and inducted with OTA $(10 \mu \mathrm{mol})$ for $24 \mathrm{~h}$. FKA treatment is predominantly responsible for restoration of the levels of intracellular GSH (Figure 4C). GSH increase could be achieved via FKA-mediated direct ROS scavenging and through the upregulation of $\gamma$-GCLC that is involved in GSH synthesis.

\subsection{Effects of FKA on Nrf2-Related mRNA Expression in OTA-Induced Endothelial Cells}

Considering the role of FKA in stimulating the pathway of Nrf2/HO-1/NQO1, we analyzed whether FKA was involved in the Nrf2/HO-1/NQO1 pathway activation in OTA-supplemented cells. The qRT-PCR results showed significant upregulation of mRNA 
$(p<0.05)$ in FKA-pretreated cells, in contrast to those treated only with OTA (Figure 4D). According to these data, FKA upregulated Nrf2 and subsequently ameliorated OTAtriggered oxidative stress.

A
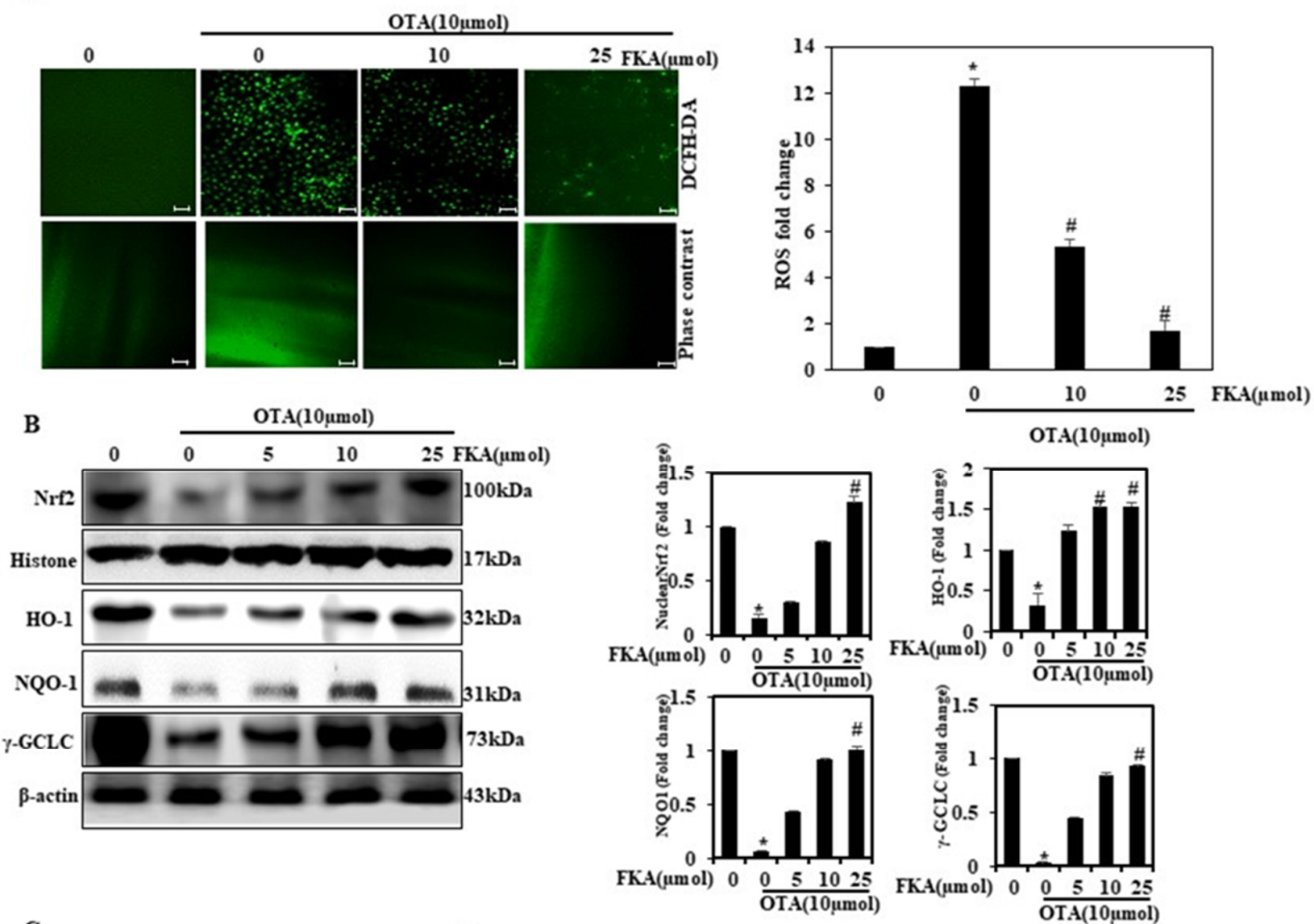

C

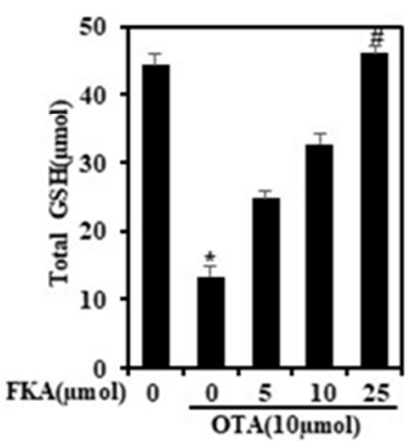

D

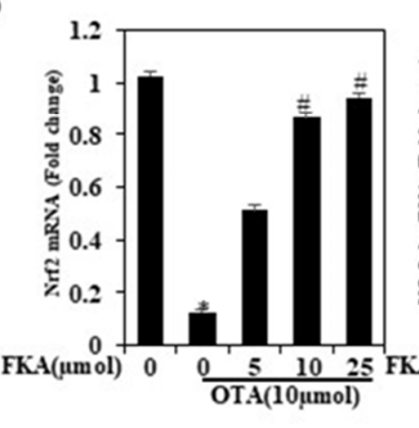

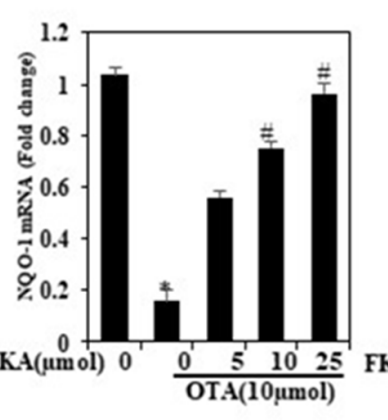

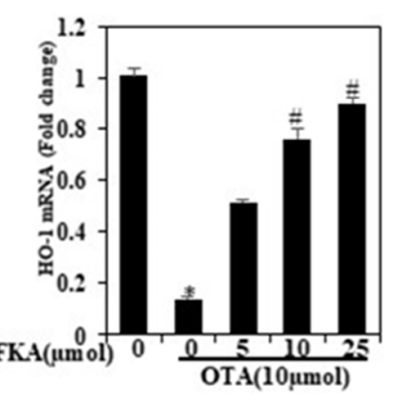

Figure 4. Effect of FKA on OTA-stimulated ROS levels, NQO-1, HO-1, and $\gamma$-GCLC antioxidant gene expression. (A) HUVECS were pretreated with FKA $(0,10$, and $25 \mu \mathrm{mol}$ for $2 \mathrm{~h})$ followed by induction with OTA $(10 \mu \mathrm{mol})$ for $24 \mathrm{~h}$. The intracellular ROS levels were measured with flow cytometry method by the DCF fluorescence technique. (B) Nuclear Nrf2 expression levels were measured andNQO-1, HO-1, and $\gamma$-GCLC proteins were regulated using WB analysis. The expressions of NQO-1, HO-1, and $\gamma$-GCLC were measured with the WB method. (C) Concentration of intracellular GSH was assayed using a commercially available ELISA kit. (D) Nrf2, NQO-1, and HO-1 expression were analyzed by RT-PCR. ${ }^{*} p<0.05$ denotes significant variations compared with the control. $\# p<0.05$ denotes significant variations as compared to OTA alone and FKA with OTA treatment groups. 


\subsection{FKA Activates OTA-Induced PI3K and AKT Phosphorylation in HUVECs}

The inhibitors of $\mathrm{pPI} 3 \mathrm{~K} / \mathrm{pAKT}$ increase the risk of vascular inflammation and endothelial dysfunction [28]. Therefore, we further checked the role of FKA in inhibiting the OTA-triggered oxidative stress via a signaling pathway such as PI3K/AKT using Western blotting. As shown in Figure 5A, we observed that OTA alone $(10 \mu \mathrm{mol})$ could downregulate the activation of pPI3K/pAKT. However, after treating the cells with FKA and OTA, the $\mathrm{pPI} 3 \mathrm{~K} / \mathrm{pAKT}$ activation was remarkably and dose-dependently upregulated. This finding suggested the protective role of FKA against OTA-induced oxidative stress via a signaling pathway such as PI3K/AKT.

A
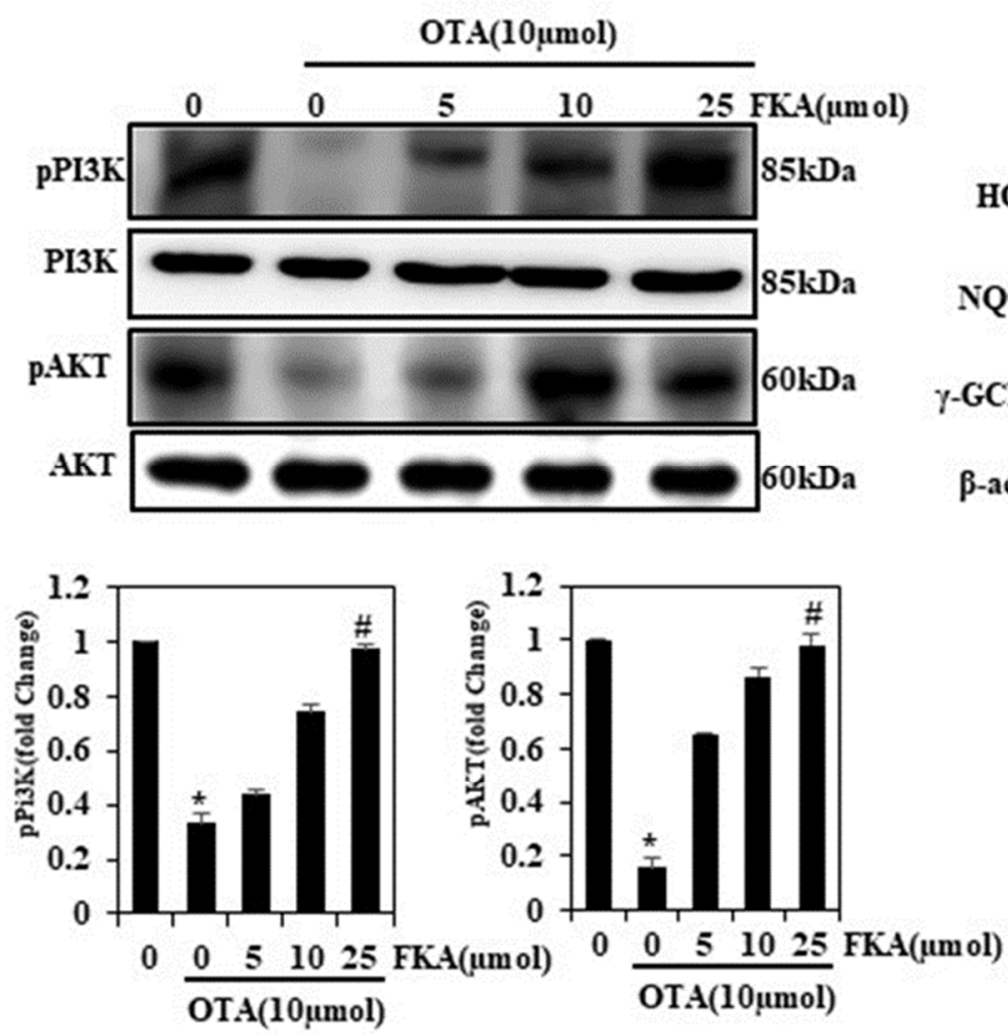

B

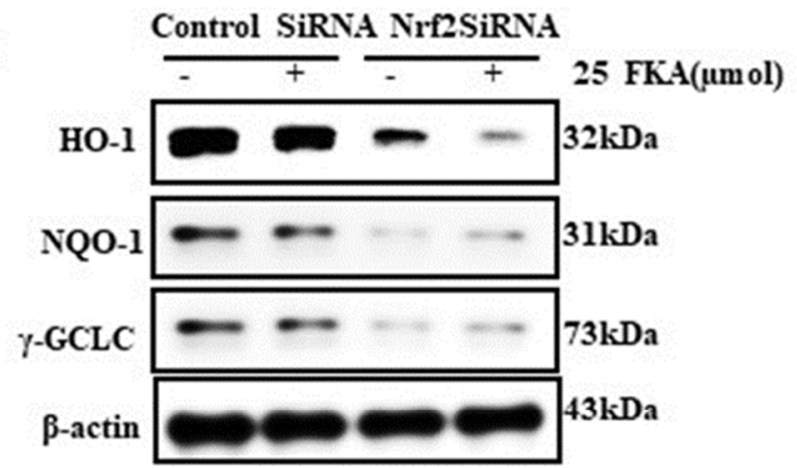

Figure 5. Effects of FKA and/or OTA on the PI3K/AKT pathways in HUVECs. Cells were pretreated with FKA (0, 10, and $25 \mu \mathrm{mol}$ for $2 \mathrm{~h}$ ) followed by induction with OTA $(10 \mu \mathrm{mol})$ for $24 \mathrm{~h}$. (A) Phosphorylation of PI3K and AKT was detected with Western blot. (B) Cells were transfected with siRNA against Nrf2 and/or a non-silencing control. The protein levels NQO-1, HO-1, and $\gamma$-GCLC were detected with Western blot analysis. ${ }^{*} p<0.05$ denotes significant variations compared with the control. \# $p<0.05$ denotes significant variations as compared to OTA alone and FKA with OTA treatment groups.

\subsection{Knockdown of Nrf2 (siRNA) Attenuated the Protective Effect of FKA on HUVECs under Oxidative Stress}

To further validate that FKA-induced Nrf2 plays a primary role in oxidative stress, Nrf2 was knocked down by siRNA transfection of Nrf2, and HO-1, $\gamma$-GCLC, and NQO-1 expressions were subsequently assayed. Western blot analysis suggested that cells that were Nrf2 knockdown and exposed to FKA $(25 \mu \mathrm{M})$ showed decreased $\gamma$-GCLC, NQO-1, and HO-1 expression (Figure 5B). This additional evidence affirmed that the FKA-activated Nrf2 signaling promoted diminished oxidative stress against OTA-induced vascular damages in HUVECs. 


\subsection{FKA Treatment Inhibits Apoptosis-Related Morphological Changes in HUVECs}

To observe if FKA treatment induced oxidative stress as a source of morphological changes associated with apoptosis, we conducted AO/EB-based dual staining. Controls and cells treated with DMSO became dark green, showing the cells' viability. It is worth noting that OTA-treated HUVECs strongly triggered the viable cells to shift to EB-positive late or dead apoptotic cells. FKA treatment also resulted in a concentration-dependent inhibition of the EB-positive apoptotic cells (Figure 6A). The result suggested that a decrease in apoptotic cell population after FKA treatment was markedly concentration-dependent.

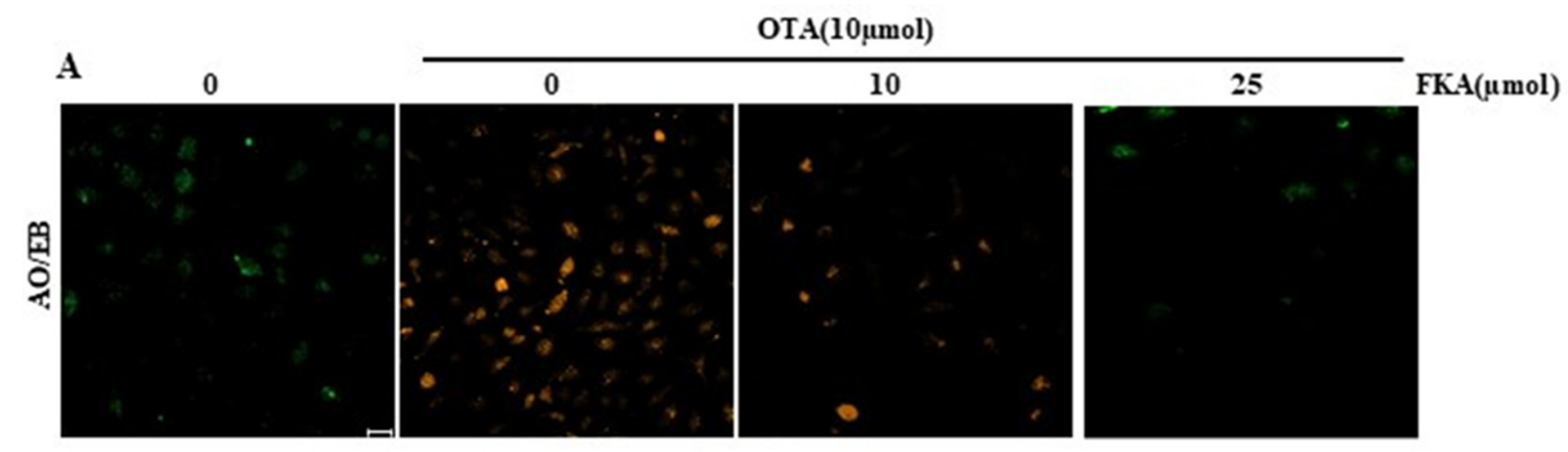

B
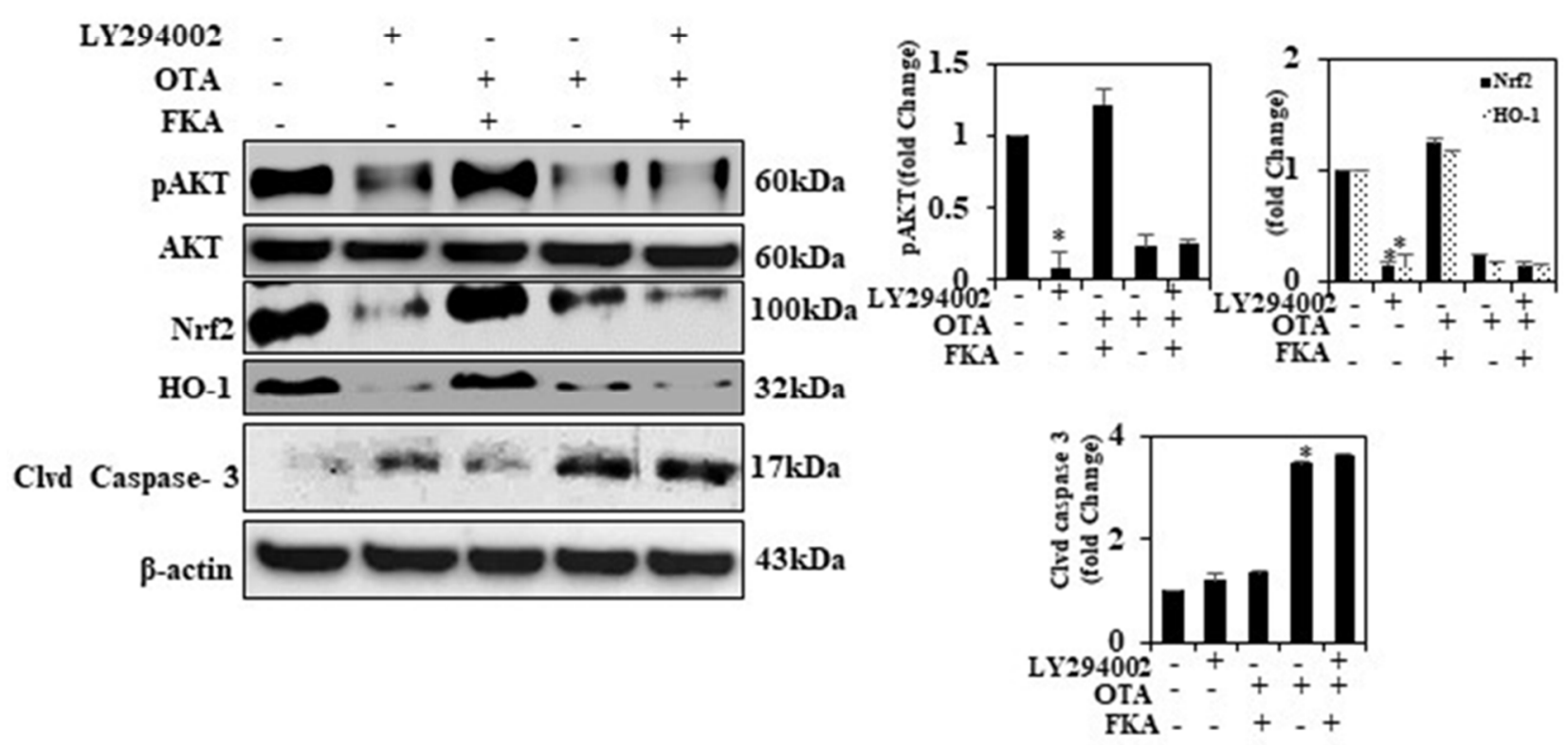

Figure 6. FKA mediates PI3K/AKT activation. Cells were pretreated with FKA (0, 10, and $25 \mu \mathrm{mol}$ for $2 \mathrm{~h})$ followed by induction with OTA $(10 \mu \mathrm{mol})$ for $24 \mathrm{~h}$. (A) Cell apoptosis observed by acridine orange/ethidium bromide (AO/EB) staining. (B) Cells were pretreated with LY294002, $(30 \mu \mathrm{M})$ for $2 \mathrm{~h}$, and FKA $(25 \mu \mathrm{mol})$ and/or OTA (10 $\mu \mathrm{mol})$ for $24 \mathrm{~h}$ to determine the pAkt, Nrf2, and HO-1 levels. ${ }^{*} p<0.05$ denotes significant variations compared with the control.

\subsection{FKA Activates PI3K/AKT Signaling to Regulate Nrf2 in OTA-Induced Endothelial Cells}

To examine whether the upregulation of pAKT was related to Nrf2 signals, we investigated Akt protein stimulation using Western blotting. In this experiment, we used a selective inhibitor, LY294002, to determine if PI3K/AKT played an important role in activating Nrf2 signaling in cells pretreated with FKA and OTA. As shown in Figure 6B, 
cells pretreated with the combination of OTA and FKA upregulated pAKT, Nrf2, and HO-1. On the other hand, LY294002-treated cells, and the combination of FKA and OTA significantly downregulated the levels of these proteins. Therefore, it was affirmed that FKA may depend on the PI3K/AKT-Nrf2 signaling regulation in HUVECs.

\section{Discussion}

The toxicity and common contamination by OTA in food and feed have garnered significant attention in the food safety and animal feed contamination sectors. There has also been a growing demand to discover effective pathways to limit the toxicity of OTA. Moreover, microbiology, toxicology, and food technology professionals have been paying special attention to OTA [11]. Various published in vitro and in vivo studies have focused on OTA nephrotoxicity and hepatotoxicity. However, the underlying mechanisms and the impact of oxidative stress on the harmful effects of these mycotoxins are not yet clear. Many researchers have studied various antioxidant compounds for their protective effects against OTA-induced organ toxicity $[29,30]$. However, there is no research on the effective protective effects of FKA against the endothelial toxicity induced by OTA. Recent studies have focused on the biological impacts of FKA for its benefits, such as anti-inflammation and antioxidant properties. Consequently, the current study explored the protective mechanism of FKA against OTA-triggered endothelial apoptosis.

For this study, we stimulated HUVECs with OTA to trigger an inflammatory reaction and subsequently demonstrated the FKA effect. According to our data, $10 \mu \mathrm{mol}$ of OTA dramatically upregulated cytokines, such as TNF- $\alpha$, IL-1 $\beta$, and IL-6. The pretreatment of cells with FKA, however, contributed to significant downregulation of TNF- $\alpha$, IL- $1 \beta$, and IL-6 secretions at all concentrations. This result indicated that FKA serves as a possible anti-inflammatory agent protecting the endothelium against inflammation.

According to recent evidence, ROS take part in inflammatory reactions. Additionally, ROS production triggered by OTA has been studied in a wide range of in vitro and in vivo systems [31-33]. For this study, it is important to note that ROS are oxidative products of the peroxisomes, mitochondria, and inflammatory cell activation of endotoxins in alveolar macrophages, and cytochrome p450 metabolism [34,35]. In concordance with the literature, our flow cytometry study data suggested that the treatment of cells with OTA alone stimulated the dramatic upregulation of the ROS levels in HUVECs. However, dosedependent FKA pretreatment significantly suppressed the previous effect. Accordingly, the Western blot data showed significant upregulation of the nuclear p65, COX-2, and TNF- $\alpha$ expressions due to OTA induction. Nevertheless, the pretreatment with FKA substantially suppressed this effect, indicating blocking of the transcriptional activation of p65, resulting in the downstream suppression of the expressions of inflammatory enzymes and cytokine proteins.

In the growth factor superfamily, PI3K is considered a key signal transduction molecule. With the help of kinases that depend on P13K, the serine and threonine residues of P13K phosphorylation contribute to the activation of AKT. According to various reports, PI3K/AKT signaling enables the regulation of ROS expression and the pathways of cellular oxidative stress [8]. It presents a survival signal, allowing Keap-1 to produce Nrf2 and its subsequent translocation, and further regulates the activation of Nrf2 that depends on ROS under various stresses, including oxidative stress. Conversely, a few researchers have suggested that some kinase pathways, such as PI3K, can restore the Nrf2-ARE activation without depending on oxidative stress [18]. To assess if FKA upregulates HO-1 via the activation of Nrf2, we isolated the protein and inspected the expression of Nrf2 protein using Western blotting. We observed that the supplementation of FKA remarkably augmented the expression of Nrf2 protein in the nucleus, suggesting its key role in stimulating the expression of $\gamma$ GCLC and HO-1 through Nrf2 signaling regulation. Furthermore, we used cells knocked down by Nrf2 to learn whether the inhibition of signaling regulated by Nrf2 improved FKA-induced HO- 1 and $\gamma$ GCLC expression. The inhibition of Nrf2 was observed to profoundly attenuate the HO-1 expression triggered by FKA. The results 
thus suggested that FKA exhibits antioxidant properties through the upregulation of the expression of HO-1 via Nrf2 signaling.

We proposed a hypothesis that PI3K/AKT plays a role in regulating FKA in cells treated with OTA. FKA supplementation dramatically increased the AKT protein phosphorylation, indicating that increased phosphorylation of the AKT protein may be involved in the expression of HO-1 stimulated by FKA. To assess the PI3K/AKT pathway function, we used a particular inhibitor of PI3K/AKT, LY294002 for HUVECs, and a combination of FKA and OTA. The findings showed that FKA induced PI3K/AKT and Nrf2 expressions. Additionally, we investigated whether PI3K/AKT played a key role in limiting the generation of ROS via FKA. Our findings indicated that the cascade of PI3K/AKT signaling plays a crucial role in FKA-triggered HO-1 expression by inducing Nrf2 in oxidative stress induced by OTA.

The stimulation of endothelial injury via OTA-induced oxidative stress results in cell apoptosis. Caspase-3 and Bcl-2 are essential proteins that stimulate the pathway of apoptotic cell death [16]. In this study, we examined the FKA mechanisms against cytotoxicity triggered by OTA. We observed that FKA slightly reversed the alteration of OTA-mediated proteins in Bcl-2, cleaved caspase-3, and cleaved PARP. Moreover, OTA can lead to HUVEC death by provoking the apoptosis of cells. Therefore, it is considered that FKA provides protection against damage caused by OTA through the blockage of the apoptotic cell death pathway. FKA may further improve the pathway of DNA repair.

\section{Conclusions}

Dysfunction of the vascular endothelium is thus a hallmark of human diseases. In this respect, the early detection and immediate treatment of endothelial dysfunction appear crucial for substantial recovery from endothelium-caused diseases. Our study findings validated that oxidative stress contributes to the mechanism of OTA endothelial toxicity, and exposure to OTA triggers adverse effects and significant transformation of endothelium functions. FKA treatment contributes to restoration of endothelium function through PI3K/AKT-mediated Nrf2 signaling. Therefore, the use of FKA for its antioxidant activity can suppress oxidative stress and decrease the biosynthesis of mycotoxins in food sources while protecting human and animal health.

\section{Materials and Methods}

\subsection{Chemicals}

We bought both OTA and FKA from LKT Labs Inc. (St Paul, MN, USA). OTA and FKA were dissolved in $0.1 \mathrm{~mol} / \mathrm{L}$ sodium bicarbonate and DMSO, respectively. For this study, we also used other analytical grade reagents.

\subsection{Cell Culture}

HUVECs were collected from the American Type Culture Collection (ATCC, Manassas, VA, USA). The cells procured were developed using ECM basal medium enriched with $10 \%$ fetal bovine serum (ThermoFisher Scientific, Waltham, MA, USA), $2 \mathrm{mM}$ glutamine (Sigma-Aldrich, St. Louis, MO, USA), $100 \mathrm{unit} / \mathrm{mL}$ penicillin (Sigma-Aldrich), $100 \mu \mathrm{g} / \mathrm{mL}$ streptomycin (Sigma-Aldrich), and $1 \mathrm{mM}$ pyruvate (Sigma-Aldrich) in humidified air (5\% $\left.\mathrm{CO}_{2}\right)$ at $37^{\circ} \mathrm{C}$.

\subsection{Cell Culture and Treatment}

We cultured the cells in a $37^{\circ} \mathrm{C}$ incubator with $\mathrm{CO}_{2}$ of $5 \%$ and passaged them $3-5$ times before using them in the experiments. After the cells were grown to $90 \%$ confluence, they were inoculated in 6- and 96-well plates. We pretreated the endothelial cells with different FKA concentrations $(0,10$, and $25 \mu \mathrm{mol}$ for $2 \mathrm{~h})$ and inducted OTA $(10 \mu \mathrm{mol})$ for $24 \mathrm{~h}$. 


\subsection{In Vitro Stimulation Assays}

In this experiment, we pretreated the HUVEC cultures for $2 \mathrm{~h}$ with FKA. The cells washed with phosphate-buffered saline were then subjected after incubation to a new medium supplemented with or without OTA (prepared in $0.1 \mathrm{~mol} / \mathrm{L} \mathrm{NaHCO}_{3}$ ). Li Zhang et al.'s (2019) study showed inflammation in HUVECs using $12.5 \mathrm{ng} / \mathrm{mL}$ TNF- $\alpha$ for $12 \mathrm{~h}$ [36]. Based on this experiment, $10 \mu \mathrm{mol}$ of OTA was used for HUVECs.

To calculate TNF- $\alpha$, IL- $1 \beta$, and IL- 6 levels in the cell culture medium, about $6.5 \times 105$ cells/well of HUVECs were cultured in a 12-well plate. The cells were pretreated with FKA $(0-25 \mu \mathrm{M}, 2 \mathrm{~h})$ followed by OTA $(10 \mu \mathrm{mol}, 72 \mathrm{~h})$, and we used the ELISA method for measuring the former's protective effect against the secretion of cytokine from cells stimulated by OTA. The ELISA kits (R\&D Systems, Minneapolis, MN, USA) quantified their respective cytokines according to the manufacturer's protocols.

\subsection{Estimation of Total Glutathione}

The GSH content was determined using the Glutathione Assay Kit (Catalog No. CS0260; Sigma-Aldrich Inc.). The samples from each treatment were cleaned with $0.9 \%$ $\mathrm{NaCl}$. The clean samples were homogenized in trichloroacetic acid $(1: 4, w / v)$ using a Teflon homogenizer and centrifuged at $3000 \times g$ and $4{ }^{\circ} \mathrm{C}$ for $10 \mathrm{~min}$. The supernatant was collected, and the GSH content of the supernatant was measured at $420 \mathrm{~nm}$ according to the manufacturer's protocol using the Varioskan Flash spectrophotometer (ThermoFisher Scientific). For measuring the total GSH content, standard curves were obtained with GSH equivalents of 0,150 , and $350 \mu \mathrm{M}$. [37].

\subsection{Western Blotting}

Post-treatment, we harvested the cells and used cold PBS to wash them. We then prepared nuclear, cytoplasmic, and total extracts in the aforementioned manner. For detecting the status of the protein, we used a Bio-Rad protein assay in each sample, with bovine serum albumin (BSA) as the reference standard. To obtain protein $(50 \mu \mathrm{g})$ in equal amounts, we used SDS-PAGE (8-15\%) and transferred the proteins to nitrocellulose membranes overnight. We blocked the membranes using $5 \%$ skimmed milk at $3{ }^{\circ} \mathrm{C}$ for $30 \mathrm{~min}$ and then incubated them for $2 \mathrm{~h}$ with the indicated primary antibodies (1:1000 dilution). Subsequently, a horseradish-peroxidase-conjugated goat anti-mouse or anti-rabbit secondary antibody (1:5000 dilution) was incubated using the nitrocellulose membranes for $1 \mathrm{~h}$. Importantly, we used an improved chemiluminescence substrate (Pierce Biotechnology, Rockford, IL, USA) for membrane development.

\subsection{Measurement of ROS Generation}

In this study, we identified the generation of intracellular ROS through fluorescence microscopy using the cell-permeable fluorogenic test DCFH2-DA [38]. Cells $\left(2.5 \times 10^{4}\right.$ cells $\left./ \mathrm{mL}\right)$ were developed in 10\% FBS-supplemented ECM basal medium, and when the cells reached $80 \%$ confluence, we replaced the culture medium. Post-treatment, we expelled and cultured the culture supernatants using non-fluorescent DCFH2-DA $(10 \mu \mathrm{M})$ in a new medium at $37^{\circ} \mathrm{C}$ for $30 \mathrm{~min}$. The production of intracellular ROS was examined through the calculation of the intracellular amassing of dichlorofluoresce in (DCF) resulting from the oxidation of DCFH2. The fluorescence emitted was calculated using LS 5.0 delicate picture arrangement examination (Olympus Imaging America Inc., Center Valley, PA, USA).

\subsection{DNA Fragmentation}

The nuclear DNA fragmentation into nucleosomal units is a distinctive feature of programmed cell death. It is a response to different apoptotic stimuli in various types of cells. In this experiment, the DNA fragmentation in OTA and/or FKA-treated HUVECS was determined using the Cell Death Detection ELISA PLUS kit (Roche Applied Science, Branford, CT, USA) as per the manufacturer's instructions as mentioned above [8]. 


\subsection{RT-PCR}

We cleaned the FKA-injected cells with PBS and used TRIzol reagent (Invitrogen, Carlsbad, CA, USA) to isolate HUVEC RNA. We then used a PrimeScript RT reagent kit to convert the RNA to cDNA, as per the manufacturer's guidelines (Takara Bio, Shiga, Japan). We then performed real-time qPCR with the SYBR Green system (Applied Biosystems, Foster City, CA, USA) and ViiA-7 Applied Biosystem (Carlsbad, CA, USA). In all genes, the expression of mRNA was standardized to the $\beta$-actin housekeeping gene expression. We determined the status of the expression of mRNA (fold change) between groups by $2-\Delta \Delta \mathrm{Ct}$ value in comparison with the non-treated (NT) samples [8].

\subsection{Cytoplasmic and Nuclear Extractions}

In this experiment, cell pellets were resuspended in Buffer I, consisting of $25 \mathrm{mM}$ HEPES at $\mathrm{pH} 7.9,5 \mathrm{mM} \mathrm{KCl}, 0.5 \mathrm{mM} \mathrm{MgCl} 2$, and $1 \mathrm{mM}$ dithiothreitol (DTT), for $5 \mathrm{~min}$ for the preparation of the cytoplasmic extracts. We then mixed this suspension with an equal amount of Buffer II containing $25 \mathrm{mM}$ HEPES at pH 7.9, $5 \mathrm{mM} \mathrm{KCl}, 0.5 \mathrm{mM} \mathrm{MgCl}$, and $1 \mathrm{mM}$ DTT. Furthermore, the suspension supplemented with the inhibitors of protease and phosphatase was added to $0.4 \%(v / v)$ NP40. We incubated the suspension samples obtained from this experiment with spin at $4{ }^{\circ} \mathrm{C}$ for $15 \mathrm{~min}$. The subsequent procedure involved the centrifugation of the lysates in a microfuge at $2500 \mathrm{rpm}$ at $4{ }^{\circ} \mathrm{C}$ for $5 \mathrm{~min}$. We then transferred the supernatants to new Eppendorf tubes. We cleaned the pellets once using Buffer II, and we added the supernatant to the cytoplasmic protein tube. For removing the residual nuclei, we centrifuged the lysates again for $5 \mathrm{~min}$ at $4{ }^{\circ} \mathrm{C}$ at $10,000 \times g$ and then emptied to new Eppendorf tubes.

For nuclear extraction, the pellets formed from the cytoplasmic extraction were incubated with Buffer III. Apart from the inhibitors of protease and phosphatase, Buffer III consisted of $25 \mathrm{mM}$ HEPES, $\mathrm{pH}$ of $7.9,400 \mathrm{mM} \mathrm{NaCl}, 10 \%$ dextrose or sucrose, $0.05 \% \mathrm{NP} 40$, and $1 \mathrm{mM}$ DTT. We rotated the lysates for $1 \mathrm{~h}$ at $4{ }^{\circ} \mathrm{C}$, followed by 10 -min centrifugation at $4{ }^{\circ} \mathrm{C}$ at $1000 \mathrm{rpm}$. It was observed that the collected supernatants contained nuclear proteins [8].

\subsection{AO/EB Stain}

We stained the cells treated with FKA $(10$ and $25 \mu \mathrm{mol})$ and OTA $(10 \mu \mathrm{mol})$ using an acridine orange/ethidium bromide (AO/EB, $100 \mu \mathrm{g} / \mathrm{mL}$ ) mixture at room temperature for $5 \mathrm{~min}$. We observed the stained cells using fluorescence microscopy (Zeiss, München, Germany) at 100× magnification. We counted over 300 cells/sample in each experiment [39].

\subsection{Transfection}

We performed transfection with a $5^{\prime}-3^{\prime}$ sequence that targets human Nrf2 siRNA. We loaded HUVECs at $1.5 \times 10^{5}$ cells per well into 6-well plates and performed transfection with Lipofectamine 2000, following the manufacturer's recommendations. Shortly after, we prepared the right amount of Nrf2 siRNA along with $5 \mu \mathrm{L}$ Lipofectamine 2000 in $250 \mu \mathrm{L}$ serum-free DMEM/12 medium in individual RNase-free tubes. The 5 min incubation of siRNA and Lipofectamine was followed by the combination and incubation for another $20 \mathrm{~min}$ and supplementation to each well. After incubating for $24 \mathrm{~h}$ with $100 \mathrm{pM}$ siRNA per well, FKA was added to the cells for protein analysis for $24 \mathrm{~h} \mathrm{[40].}$

\subsection{TUNEL Assay}

In the log phase, HUVECs were loaded into an FKA- or OTA-supplemented 6-well plate. After removing the medium, we cleaned the cells with phosphate buffer saline and processed them for about $20 \mathrm{~min}$ with $4 \%$ paraformaldehyde. This process was followed by the removal of paraformaldehyde. The cells were re-washed with phosphate buffer saline and were then subjected to incubation with TUNEL reagent (11684817910, Roche, Mannheim, Germany). We used $0.1 \mu \mathrm{g} / \mathrm{mL}$ DAPI to counterstain the washed cells for $5 \mathrm{~min}$ and studied them through a fluorescence microscope. We executed all the 
morphometric-related studies three times. TUNEL-positive cells were identified as brilliant green, whereas we observed the cell nuclei using UV light microscopy at $454 \mathrm{~nm}$. Images were obtained with microscopy $(200 \times$ magnification), and were measured using a Leica D6000 fluorescence microscope (Leica, Wetzlar, Germany).

\subsection{Statistics}

To perform statistical analyses, we used GraphPad Prism software version 6.0 (GraphPad Software Inc., San Diego, CA, USA). The three groups were compared with one-way ANOVA. Data are represented as the mean $\pm \mathrm{SD}$, and $p<0.05$ was considered significant.

Author Contributions: Conceptualization, P.R.; methodology, P.R. and E.A.A.; software, A.M.A.; validation, P.R. and V.P.V.; formal analysis, P.R. and A.M.A.; investigation, P.R. and V.P.V. resources, P.R.; data curation, P.R.; writing—original draft preparation, P.R.; writing—review and editing, V.P.V.; visualization, E.A.A.; supervision, P.R. and A.M.A.; project administration, P.R. and E.A.A.; funding acquisition, E.A.A. All authors have read and agreed to the published version of the manuscript.

Funding: This study was supported by Deanship of Scientific Research at King Fai-sal University, Al Ahsa, Saudi Arabia, grant No. 1811010, 2019.

Institutional Review Board Statement: Not applicable.

Informed Consent Statement: Not applicable.

Data Availability Statement: The data that support the findings of this study are available from the corresponding author upon reasonable request.

Conflicts of Interest: The authors declare no conflict of interest.

\section{References}

1. Rajendran, P.; Rengarajan, T.; Thangavel, J.; Nishigaki, Y.; Sakthisekaran, D.; Sethi, G.; Nishigaki, I. The vascular endothelium and human diseases. Int. J. Biol. Sci. 2013, 9, 1057. [CrossRef]

2. Nishigaki, I.; Rajendran, P.; Venugopal, R.; Ekambaram, G.; Sakthisekaran, D.; Nishigaki, Y. Cytoprotective role of astaxanthin against glycated protein/iron chelate-induced toxicity in human umbilical vein endothelial cells. Phytother. Res. Int. J. Devoted Pharmacol. Toxicol. Eval. Nat. Prod. Deriv. 2010, 24, 54-59. [CrossRef]

3. Mark, F. Injuries to the vascular endothelium: Vascular wall and endothelial dysfunction. Rev. Neurol. Dis. 2008, 5 (Suppl. S1), S4-S11.

4. Polovina, M.M.; Potpara, T.S. Endothelial dysfunction in metabolic and vascular disorders. Postgrad. Med. 2014, 126, 38-53. [CrossRef]

5. Goligorsky, M.S. Vascular endothelium in diabetes. Am. J. Physiol. Ren. Physiol. 2017, 312, F266-F275. [CrossRef] [PubMed]

6. Jamwal, S.; Sharma, S. Vascular endothelium dysfunction: A conservative target in metabolic disorders. Inflamm. Res. 2018, 67, 391-405. [CrossRef] [PubMed]

7. Vallance, P.; Calver, A.; Collier, J. The vascular endothelium in diabetes and hypertension. J. Hypertens. Suppl. Off. J. Int. Soc. Hypertens. 1992, 10, S25-S29. [CrossRef] [PubMed]

8. Potenza, M.A.; Gagliardi, S.; Nacci, C.; Carratu, M.R.; Montagnani, M. Endothelial dysfunction in diabetes: From mechanisms to therapeutic targets. Curr. Med. Chem. 2009, 16, 94-112. [CrossRef]

9. Moncada, S.; Higgs, E. Nitric oxide and the vascular endothelium. Vasc. Endothel. I 2006, 213-254.

10. Sima, A.V.; Stancu, C.S.; Simionescu, M. Vascular endothelium in atherosclerosis. Cell Tissue Res. 2009, 335, 191-203. [CrossRef] [PubMed]

11. Damiano, S.; Longobardi, C.; Andretta, E.; Prisco, F.; Piegari, G.; Squillacioti, C.; Montagnaro, S.; Pagnini, F.; Badino, P.; Florio, S.; et al. Antioxidative Effects of Curcumin on the Hepatotoxicity Induced by Ochratoxin A in Rats. Antioxidants 2021, 10, 125. [CrossRef]

12. Khaneghah, A.M.; Fakhri, Y.; Sant'Ana, A.S. Impact of unit operations during processing of cereal-based products on the levels of deoxynivalenol, total aflatoxin, ochratoxin A, and zearalenone: A systematic review and meta-analysis. Food Chem. 2018, 268, 611-624. [CrossRef]

13. Ramyaa, P.; Padma, V.V. Quercetin modulates OTA-induced oxidative stress and redox signalling in HepG2 cells-Up regulation of Nrf2 expression and down regulation of NF-кB and COX-2. Biochim. Biophys. Acta (BBA)-Gen. Subj. 2014, 1840, 681-692. [CrossRef]

14. Russo, A.; La Fauci, L.; Acquaviva, R.; Campisi, A.; Raciti, G.; Scifo, C.; Renis, M.; Galvano, G.; Vanella, A.; Galvano, F. Ochratoxin A-induced DNA damage in human fibroblast: Protective effect of cyanidin 3-O- $\beta$-D-glucoside. J. Nutr. Biochem. 2005, $16,31-37$. [CrossRef] 
15. Li, L.; Chen, Y.; Jiao, D.; Yang, S.; Li, P. Protective effect of astaxanthin on ochratoxin A-induced kidney injury to mice by regulating oxidative stress-related NRF2/KEAP1 pathway. Molecules 2020, 25, 1386. [CrossRef]

16. Rajendran, P.; Ammar, R.B.; Al-Saeedi, F.J.; Mohamed, M.E.; ElNaggar, M.A.; Al-Ramadan, S.Y.; Bekhet, G.M.; Soliman, A.M. Kaempferol inhibits zearalenone-induced oxidative stress and apoptosis via the PI3K/Akt-mediated Nrf2 signaling pathway: In vitro and in vivo studies. Int. J. Mol. Sci. 2021, 22, 217. [CrossRef] [PubMed]

17. Zhai, S.; Ruan, D.; Zhu, Y.; Li, M.; Ye, H.; Wang, W.; Yang, L. Protective effect of curcumin on ochratoxin A-induced liver oxidative injury in duck is mediated by modulating lipid metabolism and the intestinal microbiota. Poult. Sci. 2020, 99, 1124-1134. [CrossRef] [PubMed]

18. Hseu, Y.C.; Yang, T.Y.; Li, M.L.; Rajendran, P.; Mathew, D.C.; Tsai, C.H.; Lin, R.W.; Lee, C.C.; Yang, H.L. Chalcone flavokawain A attenuates TGF- $\beta 1$-induced fibrotic pathology via inhibition of ROS/Smad3 signaling pathways and induction of Nrf2/AREmediated antioxidant genes in vascular smooth muscle cells. J. Cell. Mol. Med. 2019, 23, 775-788. [CrossRef] [PubMed]

19. Rockey, D.C.; Bell, P.D.; Hill, J.A. Fibrosis-A common pathway to organ injury and failure. N. Engl. J. Med. 2015, 372, 1138-1149. [CrossRef] [PubMed]

20. Tang, Y.; Simoneau, A.R.; Xie, J.; Shahandeh, B.; Zi, X. Effects of the kava chalcone flavokawain A differ in bladder cancer cells with wild-type versus mutant p53. Cancer Prev. Res. 2008, 1, 439-451. [CrossRef]

21. Abu, N.; Ho, W.Y.; Yeap, S.K.; Akhtar, M.N.; Abdullah, M.P.; Omar, A.R.; Alitheen, N.B. The flavokawains: Uprising medicinal chalcones. Cancer Cell Int. 2013, 13, 1-7. [CrossRef]

22. Li, X.; Xu, X.; Ji, T.; Liu, Z.; Gu, M.; Hoang, B.H.; Zi, X. Dietary feeding of Flavokawain A, a Kava chalcone, exhibits a satisfactory safety profile and its association with enhancement of phase II enzymes in mice. Toxicol. Rep. 2014, 1, 2-11. [CrossRef]

23. Rajendran, P.; Chen, Y.F.; Chen, Y.F.; Chung, L.C.; Tamilselvi, S.; Shen, C.Y.; Day, C.H.; Chen, R.J. The multifaceted link between inflammation and human diseases. J. Cell. Physiol. 2018, 233, 6458-6471. [CrossRef]

24. Braud, L.; Battault, S.; Meyer, G.; Nascimento, A.; Gaillard, S.; de Sousa, G.; Rahmani, R.; Riva, C.; Armand, M.; Maixent, J.M.; et al. Antioxidant properties of tea blunt ROS-dependent lipogenesis: Beneficial effect on hepatic steatosis in a high fat-high sucrose diet NAFLD obese rat model. J. Nutr. Biochem. 2017, 40, 95-104. [CrossRef]

25. Yeap, S.K.; Abu, N.; Akthar, N.; Ho, W.Y.; Ky, H.; Tan, S.W.; Alitheen, N.B.; Kamarul, T. Gene expression analysis reveals the concurrent activation of proapoptotic and antioxidant-defensive mechanisms in flavokawain B-treated cervical cancer HeLa cells. Integr. Cancer Ther. 2017, 16, 373-384. [CrossRef]

26. Pinner, K.D.; Wales, C.T.; Gristock, R.A.; Vo, H.T.; So, N.; Jacobs, A.T. Flavokawains A and B from kava (Piper methysticum) activate heat shock and antioxidant responses and protect against hydrogen peroxide-induced cell death in HepG2 hepatocytes. Pharm. Biol. 2016, 54, 1503-1512. [CrossRef]

27. Yang, H.-L.; Yang, T.-Y.; Gowrisankar, Y.V.; Liao, C.-H.; Liao, J.-W.; Huang, P.-J.; Hseu, Y.C. Suppression of LPS-induced inflammation by chalcone flavokawain a through activation of Nrf2/ARE-mediated antioxidant genes and inhibition of ROS/NFKB signaling pathways in primary splenocytes. Oxid. Med. Cell. Longev. 2020, 2020, 3476212. [CrossRef] [PubMed]

28. Abid, M.R.; Guo, S.; Minami, T.; Spokes, K.C.; Ueki, K.; Skurk, C.; Walsh, K.; Aird, W.C. Vascular endothelial growth factor activates PI3K/Akt/forkhead signaling in endothelial cells. Arterioscler. Thromb. Vasc. Biol. 2004, 24, 294-300. [CrossRef]

29. Damiano, S.; Navas, L.; Lombari, P.; Montagnaro, S.; Forte, I.M.; Giordano, A.; Florio, S.; Ciarcia, R. Effects of $\delta$-tocotrienol on ochratoxin A-Induced nephrotoxicity in rats. J. Cell. Physiol. 2018, 233, 8731-8739. [CrossRef] [PubMed]

30. Lan, M.; Zhang, Y.; Wan, X.; Pan, M.-H.; Xu, Y.; Sun, S.-C. Melatonin ameliorates ochratoxin A-induced oxidative stress and apoptosis in porcine oocytes. Environ. Pollut. 2020, 256, 113374. [CrossRef] [PubMed]

31. Zhang, H.; Yan, A.; Liu, X.; Ma, Y.; Zhao, F.; Wang, M.; Loor, J.J.; Wang, H. Melatonin ameliorates ochratoxin A induced liver inflammation, oxidative stress and mitophagy in mice involving in intestinal microbiota and restoring the intestinal barrier function. J. Hazard. Mater. 2021, 407, 124489. [CrossRef]

32. Schmidt, L.; Heck, N.d.V.; Ferreira, I.; Göethel, G.; Somacal, S.; Emanuelli, T.; Rodrigues, E.; Garcia, S.C.; Welke, J.E.; Augusti, P.R. Ochratoxin A presence in Cabernet Sauvignon wine changes antioxidant activity in vitro and oxidative stress markers in vivo. Food Addit. Contam. Part A 2020, 37, 1755-1764. [CrossRef]

33. Ledur, P.C.; Santurio, J.M. Cytoprotective effects of curcumin and silymarin on PK-15 cells exposed to ochratoxin A, fumonisin B1 and deoxynivalenol. Toxicon 2020, 185, 97-103. [CrossRef]

34. Hou, L.; Zhou, X.; Gan, F.; Liu, Z.; Zhou, Y.; Qian, G.; Huang, K. Combination of selenomethionine and N-acetylcysteine alleviates the joint toxicities of aflatoxin B1 and ochratoxin A by ERK MAPK signal pathway in porcine alveolar macrophages. J. Agric. Food Chem. 2018, 66, 5913-5923. [CrossRef] [PubMed]

35. González-Arias, C.A.; Crespo-Sempere, A.; Marin, S.; Sanchis, V.; Ramos, A. Modulation of the xenobiotic transformation system and inflammatory response by ochratoxin A exposure using a co-culture system of Caco-2 and HepG2 cells. Food Chem. Toxicol. 2015, 86, 245-252. [CrossRef] [PubMed]

36. Zhang, L.; Wang, F.; Zhang, Q.; Liang, Q.; Wang, S.; Xian, M.; Wang, F. Anti-inflammatory and anti-apoptotic effects of stybenpropol A on human umbilical vein endothelial cells. Int. J. Mol. Sci. 2019, 20, 5383. [CrossRef] [PubMed]

37. Hseu, Y.-C.; Ho, Y.-G.; Mathew, D.C.; Yen, H.-R.; Chen, X.-Z.; Yang, H.-L. The in vitro and in vivo depigmenting activity of Coenzyme Q10 through the down-regulation of $\alpha$-MSH signaling pathways and induction of Nrf2/ARE-mediated antioxidant genes in UVA-irradiated skin keratinocytes. Biochem. Pharmacol. 2019, 164, 299-310. [CrossRef] [PubMed] 
38. Yang, H.L.; Lee, C.L.; Korivi, M.; Liao, J.W.; Rajendran, P.; Wu, J.J.; Hseu, Y.C. Zerumbone protects human skin keratinocytes against UVA-irradiated damages through Nrf2 induction. Biochem. Pharmacol. 2018, 148, 130-146. [CrossRef] [PubMed]

39. Moghtaderi, H.; Sepehri, H.; Delphi, L.; Attari, F. Gallic acid and curcumin induce cytotoxicity and apoptosis in human breast cancer cell MDA-MB-231. BioImpacts 2018, 8, 185. [CrossRef] [PubMed]

40. Rajendran, P.; Li, F.; Manu, K.A.; Shanmugam, M.K.; Loo, S.Y.; Kumar, A.P.; Sethi, G. $\gamma$-Tocotrienol is a novel inhibitor of constitutive and inducible STAT3 signalling pathway in human hepatocellular carcinoma: Potential role as an antiproliferative, pro-apoptotic and chemosensitizing agent. Br. J. Pharmacol. 2011, 163, 283-298. [CrossRef] 